\title{
Teorias que Libertam: narrativas de intelectuais brasileiros sobre engajamento em Direitos Sexuais ${ }^{1}$
}

Bruno Dallacort Zilli*

\section{Resumo}

Este artigo examina narrativas de profissionais sobre suas trajetórias intelectuais, interseccionadas por questões ligadas à equidade de gênero e direitos sexuais. 0 objetivo é descrever e entender as gramáticas emocionais que informam os discursos relativos aos engajamentos em questões políticas e intelectuais nessas temáticas. 0 papel das emoções na política é discutido no contexto da antropologia das emoções, focando na relação discursiva entre emoções, cognição e escolhas profissionais.

\section{Palavras-chave}

Gênero. Sexualidade. Emoções.

\begin{abstract}
This article examines narratives of professionals about their intellectual trajectories, intersected by issues related to gender equality and sexual rights. The objective is to describe and understand the grammars of emotions informing the discourses related to the political and intellectual engagement in these issues. The role of emotions in politics is discussed in the anthropology of emotions context, focusing on the discursive relationship between emotion, cognition and career choices.
\end{abstract}

\section{Keywords}

Gender. Sexuality. Emotions.

\footnotetext{
* Bruno Dallacort Zilli é doutor em Ciências Sociais (PPCIS/UERJ) e mestre em Saúde Coletiva (IMS/UERJ). É membro do CLAM - Centro Latino-Americano em Sexualidade e Direitos Humanos. Suas principais áreas de interesse são a antropologia das emoções e os estudos sobre saúde, gênero e sexualidade. Email: brunozilli@gmail.com.

${ }^{1}$ Este texto baseia-se na tese "Gramáticas emocionais em trajetórias de engajamento no campo de Direitos Sexuais: compaixão e vitimização a partir de narrativas biográficas de intelectuais brasileiros", defendida no Programa de Pós-Graduação em Ciências Sociais - PPCIS / UERJ, sob a orientação de Maria Claudia Coelho. Agradeço a ela e a Susana Durão pelas preciosas sugestões editoriais neste texto.
} 


\section{Introdução}

Esta investigação analisa narrativas de trajetórias profissionais a partir de um banco de entrevistas com atores pertencentes a uma rede de intelectuais e ativistas ligada ao campo intelectual latino-americano de direitos sexuais, tendo sido selecionadas as entrevistas brasileiras. $\mathrm{O}$ foco analítico incidiu sobre a temática da motivação para a ação social, buscando compreender qual gramática emotiva informa o discurso sobre a explicação para o engajamento político e intelectual em temas ligados ao gênero e à sexualidade. Esse banco de entrevistas foi eleito como um arquivo cujo exame ajuda a formular e aprofundar essas questões, aplicáveis também a outros arquivos e recortes empíricos. O aporte teórico da bibliografia da antropologia das emoções, na qual se destacam os referenciais analíticos que discutem o papel das emoções em movimentos sociais, é utilizado para pensar as narrativas em questão, com foco na relação discursiva entre a emoção e as escolhas profissionais nessas carreiras interseccionadas tanto por estudos temáticos em direitos sexuais quanto pela interlocução com movimentos sociais em diálogo com esses temas. A análise foca assim na gramática emocional presente nas narrativas sobre o engajamento relativo aos direitos sexuais e a questões de gênero e sexualidade.

As entrevistas analisadas fazem parte do projeto "Sexualidad, salud y política en América Latina: reconstrucción y análisis de una tradición intelectual de investigación", coordenado por Mario Pecheny (Instituto de Investigaciones Gino Germani - IIGG/UBA), desenvolvido no âmbito do Centro Latino Americano em Sexualidade e Direitos Humanos CLAM / IMS / UERJ ${ }^{2}$. O banco de entrevistas não é compreendido como uma amostra exaustiva ou representativa de todo o universo dos direitos sexuais, e o próprio projeto que o originou reconhece que os entrevistados foram selecionados a partir de uma rede específica, representada por interlocutores do CLAM (PECHENY, 2010).

Foram selecionadas dezesseis entrevistas. Entre elas, há três com atores estrangeiros, dois homens e uma mulher, cujos depoimentos foram incluídos por terem uma atuação importante e significativa no Brasil. Dos

\footnotetext{
${ }^{2}$ As entrevistas estão disponíveis em: <http://clam.org.br/trajetorias-intelectuais> Acesso em março de 2017.
} 
dezesseis atores, seis são homens e dez são mulheres. Entre os entrevistados, há os que focam nas questões dos direitos das mulheres, os que se dedicam aos direitos LGBT e aqueles cuja área de atuação privilegia a epidemia de HIV/ AIDS. Todos se localizam no campo das ciências humanas: dez nas Ciências Sociais, um no Direito e uma na Psicologia Social. Algumas trajetórias são acadêmicas (graduação, pós-graduação, pesquisa e ensino), enquanto outras se concentram em uma atuação profissional em ONGs. Contudo, essas atuações não são excludentes. Em alguns casos, os membros das ONGs têm passagem na academia, enquanto alguns acadêmicos atuaram em ONGs. A colaboração entre ambos é frequente, seja através de atuações conjuntas, seja através de peritos acadêmicos prestando serviço para as ONGs ou as ONGs tornandose objeto de estudos acadêmicos.

Enfatizo ainda que, embora o banco ofereça um importante panorama de uma rede de intelectuais que ajudam a constituir o campo dos direitos sexuais, não foi meu objetivo realizar uma história ou análise desse campo. $\mathrm{O}$ campo é, evidentemente, tomado como contexto das narrativas analisadas, mas aqui o principal diálogo é com a antropologia das emoções e a análise das gramáticas de engajamento num campo intelectual-político delimitado por questões ligadas ao gênero e à sexualidade. Minha preocupação central não foi fazer uma história do campo de direitos sexuais no Brasil, mas abstrair uma análise dos processos individuais de engajamento em suas temáticas. Consequentemente, escolhi tratar cada entrevista não como histórias de vida, mas como narrativas estruturadas pelo contexto em que são geradas. Neste sentido, elas tomam quase que a forma de um tipo ideal Weberiano. A despeito do caráter público do banco, optei por ocultar as identidades, omitindo nomes de atores ou instituições citados e pontos específicos das narrativas que as identificassem.

É pertinente reconhecer no desenho e desenvolvimento desta pesquisa o caráter metanarrativo que a análise possui, pois reflete sobre a minha própria trajetória e inserções institucionais que produziram os direitos sexuais como objeto de reflexão. No desenvolvimento deste trabalho, sujeito e objeto por vezes se confundem, cabendo uma reflexão sobre a análise de trajetórias de atores de um campo do qual eu mesmo faço parte. Esse elemento tem a ver com a escolha na forma de analisar as entrevistas como narrativas, desentrelaçadas dos atores que representam. Ao tomá-las como um tipo ideal, abro um espaço de análise mais confortável, escrevendo de um modo que não faça referência direta e engrossando o esforço analítico ao investir no distanciamento em relação aos atores entrevistados. Reconheço também 
que essa é uma fronteira tradicionalmente borrada no fazer antropológico, e incidir reflexivamente sobre tal questão é a melhor maneira de lidar com ela. Essa opção analítica justifica-se pelo fato de que o interesse não está nas histórias individuais pelo que têm de singular, mas sim nas suas recorrências, padrões e eventuais discrepâncias, que ajudam a identificar tensões e questões que permeiam as formas do engajamento nesse campo.

\section{Emoções e engajamento}

Há pouco mais de uma década, vêm surgindo estudos sobre o papel das emoções na esfera pública e que de fato indicam o quão fundamental é esse papel em fenômenos macropolíticos. Os organizadores da coletânea de ensaios sobre emoções e política, Passionate Politics - emotions and social movements (GOODWIN; JASPER; POLLETTA, 2001), discutem o papel das emoções em movimentos sociais buscando compreender que gramática emotiva informa o discurso sobre a motivação no engajamento político. Coelho (2010) chama atenção para o fato de que nas formulações desses autores ficam claras três concepções sobre o ator social relacionadas à questão da motivação: 1) aquela baseada na cognição, em que crenças e ideários fazem parte da mobilização; 2) aquela baseada no interesse, em que o ator social é representado como um estrategista que calcula os possíveis ganhos derivados de sua ação; um ator percebido e que se percebe como no comando das situações, mas que age de acordo com o contexto em que está inserido; e 3) aquela baseada na paixão, em que a imagem é de um ator social guiado por suas emoções, cuja motivação para participação no movimento social está no prazer inerente dessa participação. Contudo, os autores sugerem que a questão da motivação seria atravessada duplamente tanto pelas emoções quanto pelo interesse reconhecido cognitivamente.

Ao expor o desenho da coletânea, os organizadores de Passionate Politics tecem algumas importantes considerações sobre os aspectos emocionais dos movimentos sociais. Para eles, as emoções são claramente importantes na forma como os movimentos sociais e os protestos políticos crescem e se desdobram. Comumente, o primeiro passo no recrutamento de um indivíduo a um movimento social seria o "choque moral", que ocorre quando um evento ou informação não esperados causam numa pessoa uma sensação de ultraje tão forte que ela se torna inclinada à ação política, tendo ela familiaridade ou não com o movimento social associado àquela 
causa. Para os autores, da imagem de um estado de choque à do choque elétrico, fica implícita a experiência visceral e corporal do sentimento, comparável à náusea ou vertigem. Essa experiência se relaciona ao medo ou raiva causados por mudanças fora do controle de uma pessoa, que podem paralisar ou mobilizar um indivíduo. De fato, o choque moral é uma estratégia utilizada por ativistas para criar ultraje e raiva, para os quais se estabelece um alvo contra o qual esses sentimentos podem ser canalizados. Ansiedades e medos difusos precisam ser transformados em indignação e direcionados a políticas concretas e àqueles que tomam decisões. Assim, os ativistas precisam tecer uma trama moral, cognitiva e emocional que inspire à ação.

Além disto, as emoções guiariam a ação política, independentemente do cálculo sobre as chances de sucesso. O prazer da participação no movimento social pode ser grande o suficiente para manter o ativismo sem que haja uma perspectiva de conquistas políticas concretas, ao dar aos membros do movimento social reforços identitários através de sua luta e da expressão de suas perspectivas morais. Nesse sentido, o protesto é um objetivo em si mesmo. E os prazeres da participação são ainda maiores quando o movimento social compartilha uma história, elementos culturais e retóricas que são ricos e que sejam motivos de orgulho coletivo, incitando alegria, esperança e entusiasmo e reforçando o sentimento de pertencimento ao grupo.

Os movimentos sociais são também responsáveis por elaborações cognitivas acerca de sentimentos "novos", criando ou reforçando emoções que são tentativas, por vezes explícitas, de transformar visões inicialmente intuitivas em ideologias e propostas claras. Novas formas de interpretar uma situação de fato representam mudanças cognitivas que são acompanhadas por mudanças emocionais. Assim, o medo daquilo que não se compreende (numa mudança de contexto que ocasiona um choque moral, por exemplo) se transforma em ultraje diante da situação, cujo escopo é então mais bem entendido. As emoções exibidas em um protesto também podem modificar culturas emocionais mais amplas e os repertórios emocionais disponíveis a movimentos subsequentes - por exemplo, como mencionam Goodwin, Jasper e Polletta (2001), nos Estados Unidos o movimento nacionalista negro dos anos 60 tornou atraente aos movimentos feminista e gay uma "política da raiva", criando assim uma nova linguagem emocional, mais apta a expressar a relação daqueles grupos com a sociedade. 


\section{Gramáticas Emocionais de Engajamento}

As entrevistas que são objeto deste trabalho são apresentadas a seguir com citações de trechos selecionados no sentido de delinear a gramática emocional de engajamento que pode ser encontrada nessas trajetórias. $\mathrm{O}$ perfil profissional dos entrevistados é identificado entre parênteses. Nas narrativas fica em evidência o papel da inquietude diante de problemas sociais como sentimento primário que desencadeia o engajamento. Neste sentido, é explorada a relação entre cognição e emoção na determinação da mobilização política, utilizando as narrativas para demonstrar a importância de ambos e como elas se relacionam no engajamento que se dá através de uma abordagem primariamente intelectualizada.

Exemplos de "choque moral" são trazidos a partir das narrativas analisadas, e discute-se a importância da nomeação - que ocorre através da filiação teórica - para a articulação da inquietude suscitada por questões sociais ligadas ao gênero e sexualidade. Esse processo de nomeação é semelhante ao de ressignificação emocional e cognitiva descrito pelos autores de Passionate Politics, que também indicam a importância do prazer da participação em uma mobilização política (que aqui veremos com uma forte marca intelectual), que pode ser reforçada por uma rica cultura compartilhada por um grupo. Nas trajetórias, a importância do encontro com pares também é identificável, exemplificando o que os autores supracitados indicam ser o papel da coletividade para tecer uma trama moral ao redor de questões políticas.

\section{Inquietude e Satisfação: duas formas de narrar o sentimento originário do engajamento}

A estrutura narrativa nas trajetórias analisadas descreve uma gramática de engajamento intelectual e político que principia por uma inquietude diante de problemas sociais seguida por uma aproximação de formas possíveis de dar conta deles. Essa aproximação pode dar-se através de uma mobilização em direção a um registro intelectual, que pode se concretizar numa trajetória acadêmica. A mobilização também pode concretizar-se em ações relacionadas à política identitária, através da participação em instituições financiadoras, ONGs, ou em grupos de apoio. 
As narrativas se organizam em encadeamentos temáticos ao redor de explicações recorrentes para falar sobre motivação e ação. A explicação oferecida nas trajetórias para a aproximação de temas políticos se concentra inicialmente num sentimento de inquietude, que aparece sob várias roupagens. Uma delas, por exemplo, é a da indignação pessoal com atitudes entendidas como "machistas", como exemplificado no fragmento a seguir:

\begin{abstract}
"Acredito que o principal aspecto que me mobilizou nessa direção foi a minha vida de estudante universitária na luta contra a ditadura. A pegada principal foi a questão de gênero, eu como mulher, ativista, militante, com questões de mulher, eu fui uma liderança importante na luta contra a ditadura na universidade. Fundei DCE, União Nacional dos Estudantes, várias coisas assim. E sentia uma coisa de discriminação de gênero claríssima. Embora não afetasse radicalmente o que a gente fazia. Eu andava de minissaia, certo? Tem uma cena que eu lembrei recentemente relacionada a um colega trotskista na época (...). Eu estava numa assembleia, ele sentado no chão, eu falando e ele fazia assim: ‘Levanta a saia, para eu ver a calcinha. Levanta a saia, para eu ver a calcinha!'. Então, é uma coisa de uma sensibilização pessoal para a questão de ser mulher importante".

[Brasileira, atua profissionalmente na área de Psicologia Social, possui pós-graduação, é professora universitária e presta consultoria a ONGs].
\end{abstract}

A inquietude aparece também como reação à maneira de certas teorias de lidar com os problemas sociais que angustiam. No exemplo a seguir, da mesma narrativa de que foi extraído o trecho anterior, aparece o incômodo pessoal com as posições políticas do feminismo, e os campos "psi" e sexológico de um determinado contexto. Esses incômodos levam ao desenvolvimento de um ponto de vista pessoal sobre teoria, ideologia e prática que cria receptividade ao trabalho com AIDS na trajetória da entrevistada, bem como a predispõe a buscar um diálogo mais afinado com suas próprias percepções sobre questões ligadas aos direitos sexuais:

“É uma visão muito vitimizadora da mulher e que me incomodava: sem olhar a dimensão da mulher como sujeito de direitos e sujeito da sexualidade, sujeito da escolha pela maternidade, olhando a mulher como oprimida pela obrigatoriedade do casamento. Eu tinha um incômodo ideológico com essa tomada e eu quis fazer alguma coisa diferente. (...) E quando eu comecei a trabalhar com AIDS é que foi a minha virada. Eu me interessava em trabalhar 
com a sexualidade, mas na sexologia não acreditava. Porque é normativa também. Você estabelece várias queixas sexuais, vários modos de trabalhar a sexualidade normal e faz terapia sexual. É isso a sexologia. (...) A minha questão aqui é outra. Não consigo pensar dessa maneira psicopatológica. Não é esse o meu problema. Quando eu começo a trabalhar com AIDS, comecei a trabalhar com muitos jovens homossexuais. Eu fui uma das primeiras psicólogas que aceitou no seu consultório pessoas com AIDS. (...) [Eu] acolhi as pessoas com AIDS em função da questão dos direitos. Eu ficava revoltada. (...) Enquanto eu escrevia a tese de mestrado eu comecei a trabalhar com AIDS no consultório e de graça, como ativista no sistema de saúde, sem cobrar. Eu fazia supervisão, discutia, acolhia as pessoas que não podiam pagar, fazia grupo. Acompanhando as pessoas a morrer, literalmente, e achava aquilo tudo, a situação, o fim da picada".

[Brasileira, atua profissionalmente na área de Psicologia Social, possui pós-graduação, é professora universitária e presta consultoria a ONGs].

O exemplo a seguir fala, por outro lado, da satisfação com a forma de abordagem da questão feminina no contexto universitário, e depois com certas correntes do feminismo; e em especial do prazer de participar de grupos que pensavam essas questões. Também exemplifica uma crítica que revela a insatisfação com um feminismo visto como ainda muito centrado nas classes privilegiadas. Neste trecho é exatamente o binômio da satisfação e da inquietude que está articulando o engajamento. As expressões demonstrando uma relação muito positivada com as emoções associadas a essa rememoração estão sublinhadas. Este trecho revela como a construção de uma identidade intelectual pode ocorrer tanto pela inserção num grupo quanto pela oposição a outro:

“Então a gente fazia parte desse grupo [na universidade], $\underline{\mathrm{um}}$ grupo absolutamente genial (...) eram umas iniciativas bem bacanas (...) para discutir questões relevantes, para pensar a questão da mulher - e a gente falava a questão da mulher naquele momento. E tinha toda uma literatura estrangeira que eu estava conhecendo, eu estava entrando em contato. Eu fiquei fascinada. (...) E ao mesmo tempo ainda tinha uma militância militância mesmo - com grupos organizados de mulheres (...) Então, tinha um lado de militância importante, tinha um lado de intelectualidade universitária interessante e isso tudo podia ser vivido meio de uma maneira misturada. Não era tão segmentada a coisa. Então foi uma superexperiência. E, ao ter essa experiência, 
quando eu estava terminando a graduação, eu decidi que eu ia continuar. Se fosse para fazer algum mestrado, alguma pesquisa, eu queria trabalhar com isso. (...) Tinha sempre uma coisa que eu sentia que era uma barreira mesmo, sei lá, sociocultural, vamos dizer assim, entre as feministas, todas elas muito sofisticadas, vindas do exílio, classe média, com uma superformação, e as mulheres dos movimentos de mulheres (...)".

[Brasileira, atua profissionalmente na área de Ciências Sociais, possui pós-graduação e é professora universitária. Teve vínculos com ONGs e fundou centros de referência].

Associada à inquietude com temas ligados à desigualdade social, por vezes implicitamente, aparece uma satisfação com teorias capazes de dar conta dessas questões. Satisfação e inquietude são reações absolutamente complementares nessas narrativas, pois os entrevistados narram encontrar satisfação justamente na forma como certas teorias colocam em perspectiva as questões que lhes causam inquietação. Essa é uma satisfação intelectual, mas também emotiva.

A seguir, um trecho destaca uma declaração de satisfação, que aparece na forma da categoria nativa de "encantamento", para descrever o encontro com uma teoria feminista mais em sintonia com as ideias da entrevistada:

“E fazia tempo que eu não tinha contato com essa bibliografia (...). Eu tive que voltar a estudar as teorias feministas e eu fiquei absolutamente encantada, porque eu vi que tinha uma discussão muito viva, muito vigorosa. (...) e quando eu conheci, eu falei: gente, é aqui mesmo que eu quero ficar de novo".

[Brasileira, atua profissionalmente na área de Ciências Sociais, possui pós-graduação e é professora universitária. Teve vínculos com ONGs e fundou centros de referência].

A satisfação da nomeação pode ser compreendida como uma reinterpretação de perspectivas de vida, que para muitos entrevistados aparece como um "ponto de virada" em suas trajetórias. Isto acontece no exemplo seguinte, em que os contatos com as obras de Gayle Rubin, de Simone de Beauvoir ou de Michel Foucault, são narrados como pontos nodais da conversão intelectual da entrevistada:

"Quando eu fui ler Foucault direito, quando eu li Rubin, foi um ponto de virada. Eu, quando li Rubin (...) no clássico “Toward an Anthropology of Women", o livro foi publicado em 1975, 
lembro exatamente de quando eu li, foi no ano em que a minha filha nasceu, foi uma virada. Uma virada definitiva. Essas coisas que tem antes e depois. Como a Simone de Beauvoir já tinha sido. Mas a Rubin é uma virada superimportante. E Foucault também, com a "História da Sexualidade", que vem mais ou menos um pouquinho depois. (...) Eu acho que são dois marcos. Para o que eu desenvolveria depois no campo da sexualidade esse momento foi muito importante".

[Brasileira, atua profissionalmente numa ONG feminista, é fundadora e membro de ONGs que trabalham com a questão de direitos humanos. Integra redes feministas].

A sensação de satisfação aparece ainda naqueles representantes de gerações mais antigas que se envolveram com certas temáticas antes que elas estivessem totalmente estabelecidas ou legitimadas como temas políticos ou teóricos. Assim, pode haver uma expressão de satisfação em termos da percepção de envolvimento com um pioneirismo nessas temáticas. $\mathrm{O}$ pioneirismo é outra forma de expressão do prazer associado à satisfação com teorias. Esse prazer vem da capacidade de dar nome e possibilidade de resolução aos problemas que dizem respeito à inquietude fundante.

“Do ponto de vista mais próximo, eu entro nessa questão de gênero por uma pesquisa que eu estava fazendo... (...).É um trabalho interessante, talvez até um pouco pioneiro (...) Nesse trabalho, a sensação que eu tive é que eu descobri um continente submerso. Eu disse: "Aqui tem uma outra coisa acontecendo", que é a questão da mulher, na qual você identifica, de fato, um outro continente. Foi a partir daí, tudo meio convergente: eu fazendo essa pesquisa (...), as palestras do Foucault e a necessidade de procurar um diálogo com algumas pessoas que estivessem com essas inquietudes, que fugiam, digamos, à margem - era uma "terceira margem", digamos, da intelectualidade ou da esquerda naquela época. Eu me lembro que falei com uma moça que também era professora (...) e disse: "Meu Deus, estou precisando encontrar umas pessoas para conversar sobre o que eu estou encontrando nessa pesquisa. O que é, negócio de mulher?", e eu falei “É, negócio de mulher". Ela falou: "Tem um grupo aí que se reúne, elas conversam esses negócios de mulher". Eu perguntei quem eram e ela me deu alguns nomes. Peguei o telefone de alguns e perguntei: "Vocês estão conversando esses negócios de mulher?".

[Brasileira, atua profissionalmente na área de Ciências Sociais, possui pós-graduação e já foi professora universitária, é fundadora e diretora 
de uma ONG feminista e membro de vários conselhos sobre direitos humanos].

Assim, a aproximação com formas possíveis de dar conta dos problemas que causam inquietude é quase sempre marcada por uma satisfação, narrada como uma espécie de encantamento quando é direcionada a modelos teóricos que ajudam a enquadrar a percepção e/ou a lidar com os problemas que causaram a inquietude original. A satisfação pode persistir como uma relação constante de deslumbramento, às vezes relatado como uma "revelação" que foi experimentada quando se entrou em contato com determinados modelos interpretativos.

\section{0 encontro com o outro: identificação}

Collins (2001) discute a questão da dinâmica emocional dos movimentos sociais a partir da noção de "efervescência coletiva" de Durkheim (1989), que ele elabora sob o conceito de "energia emocional". Pensando em termos daquilo que revigora os elos que unem uma comunidade, a sua solidariedade, Durkheim explora os "ritos" que permitem aos indivíduos se reconectarem aos sentimentos e ideias coletivos. Exercem esse papel, por exemplo, as cerimônias religiosas. São assembleias ou eventos que reúnem todo o grupo, constituindo-se como experiência que revigora as noções de pertencimento, que reacendem a lealdade, que criam "um estado de efervescência" no plano das sensações. Assim, Durkheim coloca as relações afetivas entre os indivíduos como elo base da manutenção da sociedade e entende o indivíduo como um ser social.

Da mesma forma, os eventos que reconectam o indivíduo às representações coletivas também têm origem e função social, pois sistematizam o modo de vida, são expressão da vida social e a reinauguram a cada instante. Para Durkheim, compreender a religião é entender a forma como a sociedade cria suas categorias de organização do real. Para o autor, a religião demonstra muito de uma cultura, e tudo que tem base no pensamento religioso possui origem social. As categorias com as quais se pensa o real estão, portanto, em acordo com a sociedade que as produziu. A essência da vida religiosa, para Durkheim, é o coletivo. Ela expressa os anseios e representações que a coletividade possui, suas construções do real. O indivíduo vive no real interpretando-o de uma maneira particular à 
sua experiência de vida, no caso, religiosa.

A partir das elaborações de Durkheim sobre os rituais coletivos, Collins identifica duas transformações emocionais das quais dependem o sucesso do potencial de mobilização desses fenômenos. Uma é a amplificação, que dá o foco coletivo de uma emoção inicial. A segunda envolve a transmutação da emoção inicial num sentimento que se caracteriza pela consciência de ser carregado junto de um foco coletivo de atenção. Para Collins, é dessa emoção que brota a solidariedade e faz com que um indivíduo se sinta mais forte como membro de um grupo. Segundo ele, é aquilo a que Durkheim (1989) por vezes fez referência como "força moral", e Mauss (2003) chamou de mana - as energias sociais coletivamente transmitidas que em algumas sociedades são interpretadas como poder mágico. A operação de transformação emocional bem-sucedida é responsável pela catarse da emoção inicial e dá espaço às emoções coletivas da percepção de um foco de atenção compartilhado. Para Collins, cognitivamente a nomeação original do processo emocional permanece, até se torna mais articulada, mas ganha um fluxo positivo, uma percepção de importância maior. Collins analisa os métodos pelos quais os movimentos sociais se reúnem e se organizam para criar essa efervescência e manter a energia emocional de seus membros focalizada. Coelho (2010) analisa a contribuição de Collins da seguinte forma:

"Para Collins, em cada grupo social haveria limitações quanto à capacidade de devotar atenção a determinados tópicos ou problemas. Assim, um movimento social bem-sucedido seria aquele que conseguisse granjear para sua atuação parcela expressiva dessa "atenção coletiva". Este foco compartilhado de atenção é o ingrediente básico para a formação, nos termos de Durkheim, de uma "consciência coletiva" que apresentaria ao mesmo tempo dimensões cognitivas e morais; para que isto ocorra, contudo, não basta compartilhar o foco de atenção; é preciso também o reconhecimento mútuo entre os participantes de que os demais elegeram também o mesmo ponto como foco de sua atenção. É desta consciência de compartilhar o mesmo foco que emerge o sentimento de solidariedade do grupo, gerando assim uma "energia emocional". Para Collins, o ponto central desta dinâmica emocional é a transformação da emoção original em uma outra experiência emocional definida justamente por seu caráter compartilhado" (COELHO, 2010, p.6). 
Como identificaram os autores de Passionate Politics, a orientação ao engajamento numa determinada causa política é um processo cognitivo, um jogo de associações intelectuais e culturais que destacam uma questão como importante. Mas por si só essa percepção não é suficiente para explicar o engajamento, pois existe a possibilidade de reconhecimento de questões vistas como problemas sem que necessariamente isso leve a qualquer tipo de ação para tentar dar conta delas. Por isso é preciso identificar qual a relação emocional que permanece subjacente à determinação cognitiva da ação. Nas entrevistas analisadas, o par emotivo central de inquietude/satisfação se encontra num registro bastante intelectualizado, quase se confundindo com o ato cognitivo descrito pelos autores da coletânea, sintetizando uma satisfação com formas específicas de pensar problemas sociais e de dar-lhes resposta. Se a inquietude identifica problemas na sociedade, é através de correntes teóricas que em última análise levam a uma atuação profissional na área dos direitos sexuais que se chega à satisfação de participar de uma luta pela igualdade humana - manifestada especialmente na luta pelos direitos específicos das minorias.

\section{0 encontro com a teoria: nomeação}

A busca por identificação tem um papel importante nas narrativas para explicar questões vividas como pessoais que ganham uma nova conotação ao serem "nomeadas" por teorias. Essas questões deixam então um plano de referência meramente subjetivo e individual e passam a fazer parte de um contexto mais amplo, em um processo semelhante ao ato classificatório baseado em sistemas culturais, descrito por Lévi-Strauss como fonte de transformação de experiências pessoais idiossincráticas e possivelmente caóticas em experiências coerentes e significativas.

Esse problema é analisado por Lévi-Strauss a partir de uma discussão sobre processos decura xamânicos. A cura xamânica permite tornar pensável uma situação dada inicialmente em termos afetivos: "o xamã fornece à sua doente uma linguagem, na qual se podem exprimir imediatamente estados não formulados, de outro modo informuláveis" (1985a, p.228). A passagem à expressão verbal permite ao mesmo tempo viver sob uma forma ordenada e inteligível uma experiência anárquica e inefável, que provoca o desbloqueio de um processo fisiológico perturbador. No caso das narrativas dos entrevistados, é a teoria que exerce o papel associado por 
Lévi-Strauss ao xamã, que classifica, de acordo com um sistema simbólico, as vicissitudes da vida, permitindo a resolução de problemas.

A satisfação advinda da nomeação, que no caso das entrevistas analisadas vem através da teoria social, pode ser explicada como uma forma de alívio para algo que angustia e que fica mais fácil de lidar ao ser nomeado, exatamente como no caso da cura xamânica discutida por LéviStrauss, de "A Eficácia Simbólica" (1985a) e "O Feiticeiro e sua Magia" (1985b). No texto sobre a eficácia simbólica, Lévi-Strauss trata de um ritual xamânico executado durante um processo de parto problemático. Para o autor, o ritual é repleto de símbolos que buscam produzir no inconsciente da parturiente um facilitador para o parto difícil. Segundo Lévi-Strauss, o ritual funciona como ajuda ao parto ao transformá-lo em uma encenação de caráter mitológico de grande importância para a parturiente. Essa encenação é traduzida pelo autor como uma simbologia, uma representação metafórica do estado da parturiente e de como ele deve alterar-se para que o parto ocorra sem mais problemas. Essa alteração do estado patológico se dá através da uma "manipulação psicológica" que ajuda a parturiente a colocar ordem nos fatos que lhe ocorrem, "tornar pensável uma situação dada inicialmente em termos afetivos, e aceitáveis para o espírito as dores que o corpo se recusa a tolerar." (1985a, p.228)

Assim, a principal função do ritual é dar aos indivíduos "uma linguagem na qual podem exprimir imediatamente estados não-formulados de outro modo informuláveis" (idem). Neste sentido, o autor aproxima, em função, o xamanismo da terapia psicanalítica, comparando o método de ambas e a forma como estabelecem uma relação entre a mente conscientee inconsciente, entre fisiologia e psiquismo. Lévi-Strauss, contudo, indica quais são as importantes diferenças entre xamanismo e psicanálise. Na última, ocorre a construção de um mito individual, enquanto que, na primeira, o que se passa é a adequação a um mito coletivo. Além disto, o papel do analista é de ouvinte ("auditor"), enquanto o papel do xamã é de orador. Mas em ambos os casos se estabelece uma narrativa mítica que coloca os processos narrados em perspectiva, dando-lhes nomes e explicando-os.

A transformação da "inquietude" original, típica da estrutura narrativa da trajetória dos atores aqui analisados, em uma "satisfação" que advém do encontro com uma teoria capaz de "encantar", pode ser pensada como um processo de nomeação de ordem semelhante ao descrito por Lévi-Strauss. A "inquietude" fala justamente de um sentimento difuso, diferente de uma preocupação ou revolta com algo específico, nomeável. Nesse contexto, 
a importância atribuída ao encontro de uma teoria para pensar e de encontrar / fundar um grupo que pensa de maneira semelhante expressa a relevância do código compartilhado como fonte de construção do sentido que alivia e apazigua. No caso das narrativas dos entrevistados, é a teoria que exerce o papel associado por Lévi-Strauss ao xamã, que classifica, de acordo com um sistema simbólico, as vicissitudes da vida, permitindo a elaboração/solução de problemas. Sobretudo, sublinha-se que há afetos no encontro com uma ideia. A relação afetiva com uma teoria é estabelecida, de fato, através de experiências de ultraje e conturbação caracterizadas por um "choque moral" - como será visto a seguir - e que são elaboradas pelo encontro com essas teorias, daí sua centralidade na estrutura emocional descrita nessas narrativas.

\section{0 "choque moral"}

Os organizadores da coletânea Passionate Politics afirmam que a convicção sobre problemas, a avaliação cognitiva sobre o que é certo ou errado, não é condição suficiente para explicar a ação social. Contudo, nas narrativas aqui analisadas, a percepção do certo e do errado é identificada como explicação que se basta. Por isso mesmo, é preciso identificar nas gramáticas dessas narrativas os mecanismos que operam para que a percepção do certo e do errado mobilize os atores para a ação. Ainda seguindo as elaborações presentes na coletânea Passionate Politics, sugiro que é uma experiência de "choque moral" que permite colocar as inquietudes, e a satisfação com suas propostas de elaboração, a serviço do engajamento.

No trecho selecionado a seguir, a entrevistada fala sobre casos de assassinatos de mulheres que se tornaram um importante marco na história dos direitos femininos no Brasil. Na sua narrativa, a entrevistada fala da repercussão na sociedade e da mobilização ao redor desses casos de assassinatos como um exemplo de choque moral que não apenas a influenciou, mas ajudou a estruturar o próprio movimento de mulheres. $\mathrm{O}$ impacto moral desses assassinatos foi experimentado de forma coletiva, de maneira que na narrativa da entrevistada aparece como um elemento que teria criado receptividade na sociedade para o apelo das causas femininas.

“Há vários estudos a respeito disso e várias teses no Brasil a respeito desse momento. É impressionante como, aliado a esses 
assassinatos, aliado aos julgamentos onde o assassino ficava impune, existia a defesa, era em cima da defesa da honra. Portanto, a mulher alguma coisa cometeu para que o homem chegasse a esse extremo de cometer essa violência. E, rapidamente, quando o feminismo traz à tona, então, implementa-se um espaço de atendimento às mulheres. E isso começa a acontecer em vários estados, vários espaços semelhantes, tudo muito rapidamente. Logo teve no Rio e em outros estados. A imprensa abriu muito espaço para esse debate. Foi impressionante. Claro que a imprensa gosta de coisas muito sensacionalistas e que não era a nossa discussão, mas os fatos eram fatos de certa forma horríveis, lamentáveis e causavam de certa forma um interesse. Então, com isso, a própria televisão, a TV Globo, fez um programa, um especial de televisão, no seu horário nobre, chamado "Quem ama não mata". Porque isso era a insígnia daquilo que nós pichávamos nos muros no Brasil: 'quem ama não mata'. A televisão faz esse especial, e esse especial fica famoso. Em 1989, a televisão faz outro programa, um especial chamado "Delegacia de mulheres", tratando um pouco de algumas tipificações de crimes versus o atendimento em uma delegacia. O programa durou um ano mais ou menos. Esse foi um debate onde a reação dos conservadores ou dos machistas não encontrou eco. Eles não tiveram muito eco e foi quase como uma ola de discussão que foi encontrando muitos lugares férteis para o debate".

[Brasileira, atua profissionalmente na área de Ciências Sociais, possui pós-graduação e é professora universitária. É membro de diversos comitês e trabalhou para uma agência de financiamento de pesquisas].

O esforço daqueles já comprometidos com uma causa em estruturar um evento como um choque moral, de forma que ele tenha impacto na sociedade e seja reconhecido como tal, é um elemento que foi apontado pelos autores de Passionate Politics como parte do trabalho cognitivo realizado por membros dos movimentos sociais. Contudo, o choque moral pode ser experimentado de maneira individual. No trecho selecionado a seguir, pode-se ver um exemplo de choque moral, em que o testemunho da morte agonizante de um paciente, que na época a entrevistada atendia como psicóloga, faz com que ela coloque em perspectiva o que as teorias e métodos da psicologia social tinham a oferecer às vítimas (potenciais ou não) da epidemia de AIDS naquele momento. É a partir desse ponto que sua narrativa se estrutura para explicar em sua trajetória as opções pelo ativismo no campo do HIV / AIDS: 
“Então, a cena que eu sempre conto, a que mudou a minha vida e que me fez trabalhar com prevenção: eu chegando no hospital, grávida de oito meses, nove meses, estava com uma barriga gigantesca do primeiro filho, eu entro no hospital (...), no nono andar e, assim, [todos com] luvas, máscara e eu entro sem nada, sento do lado dele (...). E ele me chamou para se despedir, ele morreu naquela madrugada, eram cinco horas da tarde a hora que ele me chamou. E ele me falou, sem me dizer com quem, mas ele disse: "Essa é minha primeira cena sexual". E eu sempre digo que foi aí que eu entendi a coisa da cena de um jeito completamente distinto. Ele falou: "Engraçado, né? No momento em que eu estava pegando AIDS, eu não estava pegando AIDS. Eu estava me entregando para um amor, para um prazer, imaginando que eu ia viver com aquela pessoa um tempão. Planejando que aquele ato de gozo infinito se transformasse numa história de amor", isso foi um homem falando. "No momento em que eu peguei AIDS, eu não estava pegando AIDS", ele me falou assim, seis horas antes de morrer. Foi muito forte. Ficamos em silêncio e eu ouvindo isso e eu olhava para a mulher dele e para os dois filhos. [E eu pensei:] Isso aqui não vai dar certo. O que está se fazendo com prevenção não vai dar certo. Ninguém está pensando desse jeito. Não se pensa no sentido e no significado, se pensa no comportamento. Não se pensa no contexto intersubjetivo, na intersubjetividade. Não se pensa. Para mim ficou muito claro que não ia dar certo. Foi aí que eu resolvi trabalhar com prevenção".

[Brasileira, atua profissionalmente na área de Psicologia Social, possui pós-graduação e é professora universitária. Presta consultoria a ONGs].

O trecho seguinte, de um entrevistado que atua profissionalmente na área do Direito, é outro exemplo de choque moral experimentado de forma individual. Na sua narrativa, ele identifica na necessidade de decidir, como juiz federal, sobre um caso que envolvia a concessão de direitos a parceiros do mesmo sexo, um desafio intelectual. Refletir sobre essas questões, nessa ocasião, leva o entrevistado a pensar conexões, e o estimula a buscar os estudos sobre sexualidade.

“Essa relação entre sexualidade e direitos humanos só surgiu mais tarde, quando [participei da decisão sobre] um caso inédito até então, onde se discutia a discriminação por orientação sexual, a inclusão de um companheiro do mesmo sexo no plano de saúde. O caso foi bastante rumoroso na época, seja porque era inédito, seja porque era um tema que nunca tinha tido nenhum tipo de apreciação positiva por parte dos tribunais. E aí me senti no 
desafio intelectual - e pessoal -, político e como cidadão, de buscar essa aproximação - conceitual inclusive - entre direitos humanos e sexualidade a partir da discriminação por orientação sexual. Então ali começou. Começou como um compromisso profissional, que era decidir um caso, e disso eu percebi que era um excelente tema de estudo acadêmico. Foi quando eu decidi que finalmente tinha encontrado um tema para me dedicar na academia, que até então era uma vontade um pouco difusa, mas não tinha nenhum tema que efetivamente me empolgasse".

[Brasileiro, atua profissionalmente na área jurídica, possui pósgraduação e é professor universitário e funcionário público do Judiciário. Tem vínculos com ONGs].

A seguir há outro exemplo de choque moral experimentado individualmente, que diz respeito à percepção de desigualdades de classe. O impacto na trajetória da entrevistada é grande, pois sua narrativa demonstra como essa situação levou-a a buscar diálogos e experiências que a ajudassem a lidar com suas angústias pessoais, inclusive levando-a para fora do Brasil. Em última instância, essa busca leva-a a abandonar a sua área original de atuação, a arquitetura:

"Eu tenho certeza de que a minha derivação para o campo políticosocial é um efeito da ditadura militar. Eu me encaminhei para esse campo por uma inquietação com os temas da liberdade e da justiça, foi uma contingência histórica. (...) Não é uma escolha pelos temas da sexualidade, vamos dizer, é uma escolha pelas questões de liberdade e justiça... Eu fiz uma reforma, trabalhando para uma senhora rica do Rio de Janeiro, ela tinha ficado viúva, tinha saído de um apartamento de $300,400 \mathrm{~m}^{2}$ para morar num apartamento de $100 \mathrm{~m}^{2}$, e eu tive que desenhar para essa senhora a porta bonita de ferro para separar a cozinha das dependências de empregada e que tinha um segredo de cofre para ela poder trancar a passagem da cozinha para a dependência de empregados. Isso foi uma experiência muito dolorosa. Pensar que você estava gastando sua energia intelectual ou criatividade para produzir esse objeto de segregação e injustiça social, isso foi uma experiência muito dura. (...) E acho que foi por experiências como essas que eu fui como que me deslocando na direção do pensamento social e político. Era para além da minha capacidade. Eu terminei esse desenho, entreguei para ela, e fui para a casa chorar. Ela me pagou e eu fui para casa dizer: isso é insuportável, não consigo sobreviver assim. Então tem uma coisa que é mais de natureza subjetiva. E aí eu fui para a Europa, fiz um curso de etnografia e, logo depois, ciências 
das religiões. Isso foi muito estimulante".

[Brasileira, atua profissionalmente numa ONG feminista, é fundadora e membro de ONGs que trabalham com a questão de direitos humanos. Integra redes feministas].

\section{Compaixão e vitimização}

Se a inquietude expressa a identificação de problemas na sociedade, é através de teorias que em última análise levam a uma atuação na área dos direitos sexuais, seja através de seu estudo ou de um engajamento mais direto, que se chega à satisfação de participar de uma luta pela igualdade humana - manifestada especificamente aqui na luta pelos direitos específicos das minorias. Nas narrativas analisadas, a inquietude é o estado de espírito inicial que determina a trajetória de engajamento e, em especial, a sensibilidade criada para que o choque moral surta efeito. Assim, é importante iluminar o mecanismo que subjaz à inquietude. Ele está relacionado à eleição de certos sujeitos e seus problemas como dignos de compaixão, e por isso é preciso entender a dinâmica dessa emoção.

No caso das entrevistas analisadas, a narrativa sobre o que leva um indivíduo a se engajar na área de direitos sexuais vem de um sentimento de inquietude diante de desigualdades determinadas por questões de gênero e sexualidade, e uma concomitante satisfação com tomar conhecimento de formas de entender - de nomear - essas desigualdades e de se envolver em iniciativas para saná-las. Subjacente a essas emoções estaria uma gramática da compaixão que se associa às representações predominantes em nossa sociedade sobre o papel de vítima.

As figuras da mulher e das sexualidades desviantes como objetos de controle normativo têm uma ligação direta com a forma de organização do poder na nossa sociedade. Essas figuras se constituíram discursivamente no século XIX através especialmente dos saberes médicos e jurídicos, que caracterizaram esses sujeitos como alvos primários de tutela e censura, mas também potencialmente como vítimas dignas de compaixão. Esse sentimento passou a ser uma forma discursiva legítima para controlar essas figuras.

Em outras palavras, os discursos sobre elas são uma aproximação com um exercício do poder que tem como uma de suas formas tradicionalmente legitimadas a compaixão por essas "vítimas". De fato, nas narrativas 
de trajetórias de engajamento analisadas, a satisfação encontrada na mobilização em direção aos temas ligados à questão da mulher e da crítica à heteronormatividade é um importante elemento. Essa satisfação pode ser entendida como uma forma de empoderamento, e a percepção dessas figuras como objetos de compaixão é um elemento decorrente do poder discursivo que se exerce sobre elas. A compaixão que elas inspiram, porquanto seu papel de vítimas nos discursos políticos sobre esses sujeitos, é a causa da inquietude que pode ser atestada nas narrativas e que origina o engajamento, pois é a compaixão que faz a mediação entrea relação moral do indivíduo com problemas sociais. Embora essa relação se dê de forma subjetiva, ela é regida por uma gramática social baseada na sensibilidade moral a determinadas formas de vitimização.

Segundo Clark (1997), a compaixão depende do estabelecimento de uma relação de simpatia, determinada pela interação dos papéis de "simpatizante" e "simpatizado". Esses são papéis complementares e seguem regras de sentimento e de lógica social que oferecem um script que guia as pessoas na vida social, determinando as situações e relações apropriadas para se sentir, demonstrar e receber compaixão. Assim, a gramática da compaixão é parte do código moral de uma sociedade.

Além disto, o papel do "simpatizado" não é passivo, pois para Clark esse papel envolve "deixas" que convidam à compaixão dos outros. A própria natureza da compaixão exige que essas deixas não sejam frequentes nem óbvias demais a ponto de se tornarem autocomiseração ou fraqueza. Além disto, o "simpatizado" reage à simpatia dos outros, podendo apreciar, ressentir-se ou odiar a compaixão que desperta. Assim, essa gramática determina quem pode sentir compaixão por quem, quem pode pedir compaixão, quando, como e onde, e se o sentimento pode ser aceito ou negado. Para Clark, a simpatia é um importante elemento dos laços sociais.

A combinação bem-sucedida de dar e receber compaixão conecta as pessoas, construindo e fortalecendo laços sociais. Para Clark, sentir compaixão (ou sentir que se deveria sentir compaixão) acena para as fronteiras entre aqueles que merecem e evocam nossas dádivas emocionais e os que não evocam ou merecem nada. Assim, a compaixão tem um papel na localização entre o "nós" e o "eles", um importante mediador da percepção de alteridade e da identidade de um grupo.

A posição que o "simpatizado" e o "simpatizante" em potencial ocupam de acordo com os códigos morais é fundamental para determinar se haverá 
ou não compaixão. A compaixão é um ato de construção da moralidade, e a capacidade de se compadecer ou não diz algo sobre a moral dos sujeitos. Da mesma forma, há sempre um julgamento acerca do merecimento do "simpatizado". Vítimas de infortúnio, aqueles que se arrependem de seus erros, os inocentes punidos injustamente, etc., são todos merecedores legítimos de compaixão. A relação entre compaixão e código moral se estabelece através de um critério organizador baseado na responsabilidade, ou seja, se o simpatizado é culpado ou vítima de sua própria desgraça.

Nas entrevistas analisadas, não são apenas as questões relacionadas a minorias sexuais que estão em jogo, mas uma constelação maior de problemas de discriminação e sujeição ligados ao gênero e sexualidade. Assim, as narrativas falam de machismo, de homofobia, dos elementos perversos de discriminação presentes na epidemia de HIV/AIDS. Os entrevistados podem perceber-se ou não como parte das minorias atingidas por essas situações, mas identificam claramente que simpatizam com esses grupos.

As questões ligadas ao gênero e à sexualidade bem como ao papel de minorias estigmatizadas na sociedade são marcadas pela ambivalência, como demonstrado por Gould (2001). Essa ambivalência diz respeito tanto ao desejo de integração à sociedade como a uma repulsa pela discriminação. O choque moral é uma forma de dramatizar essa ambivalência numa das duas direções. No caso das pessoas que tendem a experimentar, a dramatizar o incômodo pessoal com essas questões de gênero e sexualidade de uma forma mais intelectual, o choque moral depende também de uma articulação entre experiência e teoria, que ajuda a dar nome e a colocar em perspectiva a inquietude. Nesse sentido, a compaixãoé um sentimento moral que estabelece/rompe fronteiras da alteridade, criando "identificação", e o

choque moral pode ser percebido como um "drama" capaz de injetar afeto na cognição, assim motivando o engajamento.

\section{Considerações Finais}

Neste texto apresentei uma proposta de compreensão do cenário dos direitos sexuais no Brasil através da análise da gramática de engajamento presente nas narrativas em entrevistas com atores de uma determinada rede desse campo acerca de suas trajetórias profissionais. Segundo a análise sugerida pelos autores de Passionate Politics, a percepção de questões 
sociais como problemas inquietantes é um processo racional, cognitivo; mas por si só não explica o engajamento. Assim, é preciso entender as emoções que permanecem subjacentes a esse processo. No caso das entrevistas analisadas, o sentimento que leva um indivíduo a se engajar na área de direitos sexuais vem de uma inquietude diante de desigualdades determinadas por questões de gênero e sexualidade, e uma concomitante satisfação com tomar conhecimento de formas de entender - de nomear essas desigualdades e de se envolver em iniciativas para saná-las.

A análise dessas narrativas teve como foco a noção de "choque moral" um momento na trajetória de um indivíduo ligado a uma insatisfação pessoal com questões sociais que o leva a uma reavaliação de suas perspectivas de vida e que o conduz para uma tomada de iniciativa para sanar sua insatisfação. $\mathrm{O}$ "choque moral" é uma porta para uma epifania. A partir do problema da relação entre cognição e afeto, a análise dessas trajetórias indica que é o conteúdo moral de suas interpretações que faz a ponte entre a identificação de problemas e o engajamento, permitindo passar da cognição para o afeto que mobiliza. Contudo, essas são narrativas de trajetórias de engajamento intelectual, em que a dimensão cognitiva permanece tendo um peso significativo pela via da satisfação pela nomeação. Assim, o elemento moral é articulado pela via da subscrição a correntes intelectuais. Essas correntes são pensadas aqui como "teorias que libertam", ou seja, ideias que organizam o mundo de uma forma em que a diversidade sexual e a igualdade entre os gêneros são vistas como positivas e, sob a égide dos direitos humanos, se torna possível pensar em formas para se reduzir a discriminação e a desigualdade na sociedade.

Essas teorias são apenas algumas das alternativas disponíveis em nossa cultura para significar a sexualidade e o gênero. Por exemplo, explicações baseadas em perspectivas tradicionais, geralmente ligadas à religiosidade, oferecem também às mulheres e LGBTs um lugar no mundo, ainda que seja um lugar marginal. Contudo, essas visões de mundo - ou "teorias que angustiam" - estão em contraposição aos ideais libertários dos direitos humanos.

A partir da proposição de que as correntes intelectuais adotadas pelos atores dessas narrativas são "teorias que libertam", discuti a importância da identificação e da nomeação para a gramática emotiva de engajamento nessas entrevistas. A identificação é um elemento-chave que diz respeito ao pertencimento a um grupo associado às teorias sociais e às formas de iniciação nele. A nomeação, por sua vez, diz respeito a uma forma positiva 
de entender e dar sentido às angústias iniciais que aparecem nessas narrativas como inquietudes. Argumentei assim que através da subscrição a certas correntes de pensamento e grupos intelectuais se desenvolve uma identidade social ligada à defesa dos ideais humanitários. Essa defesa é possível graças à nomeação que a teoria social permite realizar, simbolizando de forma positiva dentro de um universo cultural as angústias e inquietações que surgem diante do incômodo fundante representado pela compaixão diante das figuras da mulher e de LGBTs. A gramática da compaixão é um elemento importante para entender a inquietude identificada na origem do engajamento das narrativas analisadas, e em especial para recolocá-la numa perspectiva macropolítica.

\section{Referências}

CLARK, Candace.

(1997). Misery and Company - sympathy in everyday life. Chicago / London, The University of Chicago Press.

COELHO, Maria Claudia.

(2010). As Emoções e a Ordem Pública: uma investigação sobre modelos teóricos para a análise sócio-antropológica das emoções. $27^{a}$ Reunião Brasileira de Antropologia. Belém, Pará.

COLLINS, Randall.

(2001). Social Movements and the Focus of Emotional Attention. In: Jeff Goodwin; James M. Jasper; Francesca Polleta (Orgs.); Passionate Politics - emotions and social movements. Chicago / London, University of Chicago Press.

LÉVI-STRAUSS, Claude. (1985a). A Eficácia Simbólica. In: Antropologia Estrutural. Rio de Janeiro, Tempo Brasileiro.

LÉVI-STRAUSS, Claude.

(1985b). 0 feiticeiro e sua magia. In: Antropologia Estrutural. Rio de Janeiro: Tempo Brasileira.
GO0DWIN, Jeff; JASPER, James M.; POLLETTA, Francesca (Orgs.).

(2001). Passionate Politics - emotions and social movements. Chicago / London, The University of Chicago Press.

GOULD, Deborah.

(2001). Rock the Boat, Don't Rock the Boat, Baby: Ambivalence and the Emergence of Militante AIDS Activism. In: Jeff Goodwn; James M. Jasper; Francesca Polleta (Orgs.); Passionate Politics - emotions and social movements. Chicago / London, University of Chicago Press. p. 135-157.

PECHENY, Mário.

(2010). Sexualidad, salud y política en América Latina: reconstrucción y análisis de una tradición intelectual de investigación. Buenos Aires: Proyectos de Investigación Científica o de Innovación Tecnológica - Programación Científica 2011-2014. Universidad de Buenos Aires. Secretaría de Ciencia y Técnica.

\section{Recebido em}

dezembro de 2016

Aprovado em

março de 2017 